\title{
OZÔNIO TROPOSFÉRICO E COMPOSTOS ORGÂNICOS VOLÁTEIS EM REGIÃO IMPACTADA PELA AGROINDÚSTRIA CANAVIEIRA
}

\author{
Ana Paula Francisco ${ }^{\mathrm{a} *}$, Débora de Souza Alvim ${ }^{\mathrm{b}}$, Luciana Vanni Gattic, Célia Regina Pesqueroa e João Vicente de Assunção ${ }^{\mathrm{a}}$ \\ a'Departamento de Saúde Ambiental, Faculdade de Saúde Pública, Universidade de São Paulo, 01246-904 São Paulo - SP, Brasil \\ 'Instituto Nacional de Pesquisas Espaciais, 12630-970 Cachoeira Paulista - SP, Brasil \\ ${ }^{c}$ Centro de Ciência do Sistema Terrestre, Instituto Nacional de Pesquisas Espaciais, 12227-010 São José dos Campos - SP, Brasil
}

Recebido em 14/03/2016; aceito em 25/05/2016; publicado na web em 20/07/2016

\begin{abstract}
TROPOSPHERIC OZONE AND VOLATILE ORGANIC COMPOUNDS ON A REGION IMPACTED BY THE SUGARCANE INDUSTRY. The purpose of this study was to evaluate the concentrations of tropospheric ozone and VOCs under the sugarcane agroindustry emissions in urban and rural areas of Araraquara, SP. The sampling was performed using active and passive air samplers during the sugarcane harvest and in the period between harvests in 2011 and 2012. Also, canisters were undertaken in 3 situations: during and after the burning of the cane plantations and in an urban area. Instrumental analysis was carried out using gas and ion chromatography. The highest VOC concentrations were found for toluene and d-limonene at the urban area and for ethene during the burning of sugarcane. Although sugarcane industry is an important emission source of ozone precursors, in this study the tropospheric ozone levels do not increased significantly under sugarcane agro-industry emissions.
\end{abstract}

Keywords: air pollution; sugarcane emissions; tropospheric ozone; volatile organic compounds.

\section{INTRODUÇÃO}

O estado de São Paulo possui 51,7\% da área cultivada com cana-de-açúcar no Brasil, representando cerca de cinco milhões de hectares. ${ }^{1}$ Desse total, a área de cana colhida utilizando queima pré corte reduziu de $65,8 \%$ em 2006 para $27,4 \%$ em 2012 como resultado da substituição da colheita manual pela mecanizada. ${ }^{2}$ Segundo a Lei estadual N. 11.241/2002, a queima pré corte deve ser totalmente eliminada até 2031, porém o Protocolo Agroambiental do Setor Sucroenergético, um acordo firmado entre os produtores do setor sucroalcooleiro do estado de São Paulo, estabeleceu a eliminação da queima de cana até $2017 .{ }^{3}$

Estudos têm indicado que a emissão de poluentes da queima da cana pré corte é importante fonte para formação de ozônio, ${ }^{4-6}$ além de produzir efeitos nocivos na saúde da população..$^{7-9}$ No processo de queima da cana pré corte foram identificadas substâncias precursoras de ozônio, como compostos aromáticos, compostos carbonílicos, ácidos carboxílicos e óxidos de nitrogênio (NOx). Em estudo de Lopes, ${ }^{10}$ formaldeído e acetaldeído foram os carbonílicos mais abundantes em emissões de queima da cana com concentrações entre 2,9 a 60 ppb; em termos de fator de emissão (quantidade de substância emitida por massa de cana queimada) a variação foi de 44,8 a $524 \mathrm{mg} \mathrm{kg}^{-1}$. Entre os aromáticos o benzeno predominou, seguido por tolueno, naftaleno, etilbenzeno, estireno e $o, m, p$-xilenos com fatores de emissão entre 0,29 e $16,5 \mathrm{mg} \mathrm{kg}^{-1} \cdot{ }^{11} \mathrm{Da}$ Rocha et al. ${ }^{12}$ identificaram os ácidos fórmico e acético em emissão de queima de cana em concentrações que variaram entre 360 e 4.230 ppb. Além desses COV, NOx foi encontrado em concentrações de 1 a 100 ppm em queima de canavial ${ }^{6,13} \mathrm{e}$ pico de 38 ppm em experimento de queima da cana em laboratório. ${ }^{14}$

A queima do bagaço de cana-de-açúcar nas caldeiras das usinas de açúcar e álcool é outra importante fonte de emissão de poluentes do setor sucroalcooleiro, que está sob regulação. A Resolução CONAMA N. 382/2006 estabelece limites de emissão para material particulado, monóxido de carbono e NOx na queima do bagaço nas caldeiras. No licenciamento das usinas de açúcar e álcool, deve-se garantir que emissão máxima de NOx será de $350 \mathrm{mg}\left(\mathrm{N} \mathrm{m}^{3}\right)^{-1}$ e entre 1300 a $3250 \mathrm{mg}\left(\mathrm{N} \mathrm{m}^{3}\right)^{-1}$ para $\mathrm{CO}$, dependendo da potência da caldeira. Além da queima de canaviais pré colheita e da queima do bagaço nas caldeiras, outras fontes de emissão de precursores de ozônio são: frota de veículos automotores à diesel para plantio, manutenção dos canaviais, colheita mecanizada e transporte de cana por treminhões e caminhões, além de combustão e perdas evaporativas por exaustão de veículos leves e compostos orgânicos não queimados em caldeiras. ${ }^{15}$

O impacto dos COV na formação do ozônio depende da reatividade e quantidade de cada composto e da concentração de NOx na atmosfera. Quando a concentração de NOx é moderadamente alta (NOx > 0,3 ppb), os COV tem papel dominante na formação de ozônio potencializada pela maior concentração e reatividade desses compostos. ${ }^{16,17}$ A reatividade dos hidrocarbonetos em relação à reação com o radical $\mathrm{OH}$ segue a seguinte ordem: ${ }^{17}$ alcenos com ligações duplas (e.g. 2-metil-2-buteno), d-limoneno $>$ di e trimetil aromáticos (o,m,p-xilenos; 1,2,4-trimetilbenzeno; 1,3,5-trimetilbenzeno > tolueno, benzeno, eteno $>\mathrm{CO}$, etano, acetileno $>$ metano. De acordo com Lopes, ${ }^{10}$ o formaldeído e acetaldeído foram os carbonílicos emitidos na queima de cana com maior potencial de contribuição para formação de ozônio.

Apesar da agroindústria canavieira apresentar diversas fontes de emissão de precursores de ozônio, existe escassez de trabalhos sobre a influência dessa atividade nas concentrações de ozônio troposférico e seus precursores. Em Araraquara, município localizado na maior região produtora de cana-de-açúcar do estado de São Paulo, ${ }^{1}$ existem importantes estudos que avaliaram a concentração de NOx, ${ }^{6,18}$ ozônio ${ }^{6,19}$ e compostos carbonílicos da queima pré corte, ${ }^{10}$ entretanto, os níveis de ozônio e COV ainda não foram avaliados conjuntamente nessa região. Por isso, considerando a iminente mudança do cenário de emissões atmosféricas da agroindústria canavieira no Estado de São Paulo e seu potencial de emissão de poluentes atmosféricos, o objetivo deste estudo foi de avaliar as concentrações de ozônio troposférico e Compostos Orgânicos Voláteis em área com influência de emissões da agroindústria de cana-de-açúcar. 


\section{PARTE EXPERIMENTAL}

\section{Área de estudo}

O estudo ocorreu em áreas urbana e rural de Araraquara, SP (Latitude: $21^{\circ} 47^{\prime} 41^{\prime \prime S}$ Longitude: $48^{\circ} 10^{\prime} 34^{\prime \prime W}$ ). Esse município está situado em região produtora de cana-de-açúcar, onde o clima é o tropical de altitude, com inverno seco e verão chuvoso, apresentando temperatura média mensal superior a $18{ }^{\circ} \mathrm{C} .{ }^{20} \mathrm{Na}$ região sudeste do Brasil, o período de safra de cana-de-açúcar ocorre, normalmente, entre maio e outubro, com pico de produção entre julho e setembro.

Em área urbana foram selecionados 6 pontos mostrados na Figura 1a, dois pontos localizados em área central: SESA e CETESB e mais 4 locais sendo um ao norte, um ao sul, a leste e oeste destes pontos.

Em área rural foram selecionados 3 pontos próximos aos canaviais durante a queima pré-corte como mostra a Figura $1 \mathrm{~b}$.

\section{Material de coleta}

Ozônio: Foram utilizados coletores passivos da $O g a w a^{\circledR}$, compostos por uma cobertura de PVC e um corpo cilíndrico de teflon (2 $\mathrm{cm}$ de diâmetro x $3 \mathrm{~cm}$ ) contendo em cada extremidade um filtro de fibra de quartzo de $14 \mathrm{~mm}$ de diâmetro. Estes filtros foram preparados em laboratório, sendo impregnados com solução de nitrito de sódio em $\mathrm{pH}$ alcalino de acordo com Campos et al. ${ }^{21}$ Cada amostra é composta por um par de filtros.

COV: Foram utilizados dois tipos de coletores de COV: tubos Tenax-GR da Supelco ${ }^{\circledast}$ com eficiência na adsorção de hidrocarbonetos a partir de $\mathrm{C} 6$ e canister (fornecidos pela Rasmussen ${ }^{\circledR}$ ) para coleta de $\mathrm{COV}<\mathrm{C} 4$. Os tubos de aço inox de Tenax-GR possuem $1,7 \mathrm{~cm}$ de comprimento e $0,181 \mathrm{~cm}^{2}$ de área da seção transversal e são empacotados com óxido de 2,6-difenil-p-fenileno com $23 \%$ de carbono grafitizado. ${ }^{22}$ Foram utilizados canisters de aço Inox com volume de $6 \mathrm{~L}$.

Antes das coletas, os tubos de Tenax GR foram limpos utilizando dessorvedor térmico (Perkin Elmer modelo Turbo Matrix 350) em temperatura de $290{ }^{\circ} \mathrm{C}$ sob fluxo de Hélio de $100 \mathrm{~mL} \mathrm{~min}^{-1}$ por 30 minutos. Após o tratamento térmico, os tubos foram vedados com tampas de latão e anilhas de Teflon, revestidos com papel alumínio e armazenados em recipiente contendo carvão ativado em refrigerador. Os canisters foram submetidos a um sistema automático de limpeza (Xontech U.S.A.) com ciclos alternados de vácuo e vapor d'água, ambos com aquecimento de $120^{\circ} \mathrm{C}$ e, ao final, mantido em alto-vácuo.

\section{Amostragem}

Amostragem em área urbana foi realizada em seis campanhas que aconteceram uma vez por mês, sendo três durante o período da safra de cana-de-açúcar (julho, agosto e setembro de 2011) e três durante período de entressafra (dezembro/2011, janeiro e fevereiro/2012). As condições meteorológicas dos períodos de amostragem apresentam-se na Tabela 1.

Coleta em área rural foi realizada nas três campanhas do período de safra de cana-de-açúcar.

Coletas passivas dos COV ocorreram em paralelo com as coletas passivas de ozônio somente na área urbana. Os coletores ficaram expostos durante 4 dias consecutivos, entre segunda e sexta-feira. No ponto de coleta "CETESB", as amostras foram coletadas em duplicatas para ozônio e COV para verificação da precisão dos métodos utilizados. Além disso, foram avaliados os resultados obtidos com o coletor passivo de ozônio em relação aos do coletor ativo automático da estação de monitoramento da Companhia Ambiental do Estado de São Paulo (CETESB).
Coletas ativas dos COV foram realizadas apenas no ponto de coleta SESA (Figura 1). Foi utilizado amostrador sequencial Perkin Elmer modelo STS-25 equipado com bomba de sucção da SKC modelo 222-4, com fluxo médio de 46,76 $\pm 2,29 \mathrm{~mL} \mathrm{~min}^{-1}$. Foram coletados 24 tubos em cada campanha, com tempo de amostragem de $1 \mathrm{~h}$ para cada tubo, por um período de $24 \mathrm{~h}$ de amostragem.

Coletas de COV com canisters foram realizadas nas três campanhas do período de safra de cana-de-açúcar em área rural e no ponto SESA (Figura $1 \mathrm{~b}$ ). Na área rural foram coletadas amostras em período noturno em local próximo ao canavial durante a queima da palha (a partir das 20 h) e no mesmo local na manhã seguinte após a queima (cerca de $8 \mathrm{~h}$ depois). Durante as coletas próximas aos canaviais, os canisters foram posicionados em direção à pluma de emissão da queima e instalados a 1,5 m de altura do solo, $5 \mathrm{~m}$ de distância do canavial. As amostragens com canisters foram reguladas por um controlador de fluxo (Veriflo SC423XL) de $100 \mathrm{~mL} \mathrm{~min}^{-1}$, durante o período de $1 \mathrm{~h}$, totalizando $6 \mathrm{~L}$ em cada amostra. No ponto SESA, coletas com canisters foram realizadas cerca de $7 \mathrm{~h}$ após a queima do canavial. No total, nove amostras foram coletadas com canisters.

As amostras foram armazenadas e transportadas em temperatura de $\sim 4^{\circ} \mathrm{C}$ com exceção dos canisters. Brancos de campo foram utilizados durante o transporte, armazenamento e instalação dos coletores.

\section{Extração e análise das amostras}

Ozônio: Após o período de exposição, cada par de filtro do coletor Ogawa foi transferido para frasco contendo $5 \mathrm{~mL}$ de água ultrapura e submetido à agitação mecânica por $15 \mathrm{~min}$. $\mathrm{O}$ extrato foi filtrado em membrana de $0,22 \mu \mathrm{m}$ (Millipore ${ }^{\circledR}$ ). Os íons nitrato, produto da reação entre o reagente de impregnação e o ozônio, ${ }^{18}$ foram analisados em cromatógrafo iônico (Metrohn Compact IC/ 761) equipado com coluna analítica Metrosep A Supp 5 (150 x $4 \mathrm{~mm}$ ), eluente $\mathrm{Na}_{2} \mathrm{CO}_{3}$ $\left(3,2 \times 10^{-3} \mathrm{M}\right) / \mathrm{NaHCO}_{3}\left(1,0 \times 10^{-3} \mathrm{~mol} \mathrm{~L}^{-1}\right)$ e fluxo de $0,7 \mathrm{~mL} \mathrm{~min}{ }^{-1}$. Detecção foi obtida por detector de condutividade elétrica. Curva analítica foi preparada com concentrações que variaram entre 0,32 a $8,0 \mu \mathrm{g} \mathrm{mL} \mathrm{m}^{-1}$. Limite de quantificação do método foi de $0,08 \mathrm{ppm}$.

COV: As amostras coletadas em tubos foram submetidas à dessorção em dessorvedor térmico Turbo Matrix 350 Perkin-Elmer, acoplado em Cromatógrafo a Gás Agilent modelo 6890N/Espectrômetro de Massas Agilent modelo 5973. A dessorção dos tubos foi a 250 ${ }^{\circ} \mathrm{C}$ por $15 \mathrm{~min}$ a um fluxo de Helio (6.0 Bip) de $50 \mathrm{~mL} \mathrm{~min}{ }^{-1}$, com pré-concentração em trap frio a $-30{ }^{\circ} \mathrm{C}$ seguido de aquecimento a $250{ }^{\circ} \mathrm{C}$ em $7 \mathrm{~s}$ para injeção no CG. A separação dos COV foi feita em coluna Elite 624 (6\% cyanopropyl; $94 \%$ dimethylpolysiloxane) com $60 \mathrm{~m}$ de comprimento, 0,25 mm de diâmetro interno e 1,40 $\mu \mathrm{m}$ de espessura de filme. No espectrômetro de massas foram feitas análises com métodos SIM (Single Ion Monitoring) e SCAN simultâneos para quantificação e confirmação dos espectros. Curvas analíticas foram construídas com método SIM para 42 compostos em concentrações que variaram de 5 a $200 \mu \mathrm{g} \mathrm{mL} \mathrm{m}^{-1}$. Os limites de quantificação para os COV variaram entre 0,09 e 5,3 ng/amostra.

Alíquotas de amostras contidas nos Canisters foram injetadas no sistema de análise com pré-concentração criogênica em temperatura de $-180{ }^{\circ} \mathrm{C}$ seguida de aquecimento a $200{ }^{\circ} \mathrm{C}$ (em 20 segundos) sob fluxo de gás de arraste (Hélio). Foram utilizados dois cromatógrafos para análise dos compostos. COV com quatro carbonos ou mais foram identificados e quantificados utilizando CG (VARIAN 3800/ SATURN 2000), com coluna capilar DB-1 (60 m x 0,32 mm x $1 \mu \mathrm{m})$, acoplado aos detectores de espectrometria de massas e ionização de chama (MS-FID) simultaneamente. Os COV entre C2-C3 foram analisados por CG (VARIAN 3800) com coluna PLOT (50 m x 0,53 mm x $10 \mu \mathrm{m})$ e detecção por ionização de chama. A curva analítica foi preparada a partir de padrão gasoso, produzido e certificado pela 


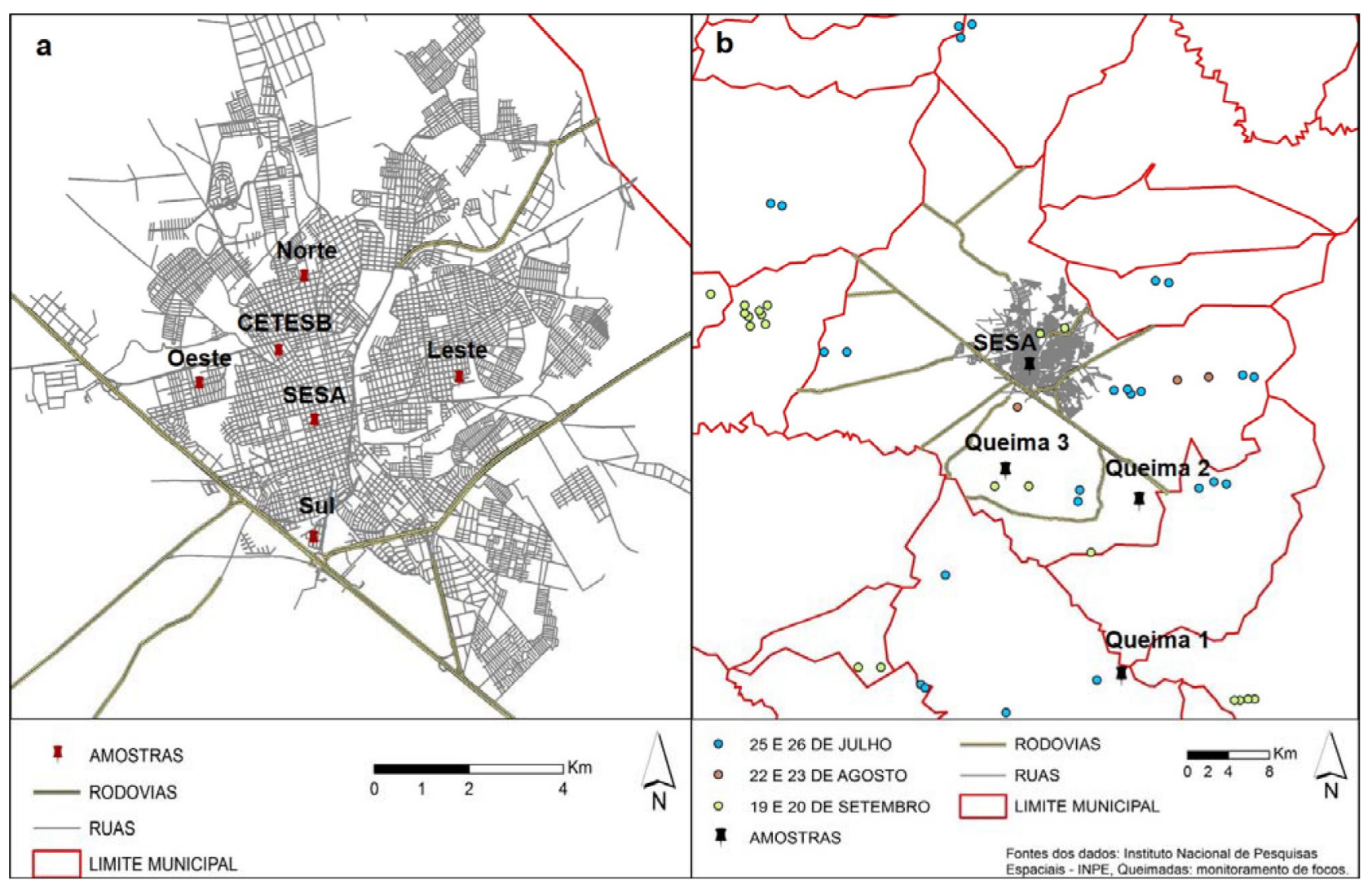

Figura 1. Mapa indicando locais de amostragem na cidade de Araraquara, SP. SESA corresponde ao Serviço Especial de Saúde de Araraquara, e CETESB corresponde a estação automática de qualidade do ar da Companhia Ambiental do Estado de São Paulo. Fig. 1a: distribuição de seis pontos de coleta na área urbana. Fig 1b: localização dos três pontos em área rural, ponto de coleta urbano (SESA) e os focos de queimadas registrados durante as coletas com canisters na safra de cana-de-açúcar

Tabela 1. Condições meteorológicas na safra e entressafra do período de estudo

\begin{tabular}{lccccccc}
\hline & & Safra & & \multicolumn{3}{c}{ Entressafra } \\
\cline { 2 - 4 } \cline { 5 - 7 } & Mín. & Máx. & Média & & Mín. & Máx. & Média \\
\hline Velocidade do Vento $\left(\mathrm{m} \mathrm{s}^{-1}\right)$ & 1,00 & 5,20 & 2,41 & & 1,00 & 5,00 & 2,32 \\
Temperatura $\left({ }^{\circ} \mathrm{C}\right)$ & 15,5 & 33,7 & 23,0 & & 18,1 & 36,1 & 25,0 \\
Umidade Relativa $(\%)$ & 21,0 & 90,0 & 49,6 & & 10,0 & 63,3 \\
\hline
\end{tabular}

National Physical Laboratory (NPL, Teddington Middlesex, UK TW11 OLW), contendo mistura de COV precursores de ozônio da classe dos alcanos, alcenos, aromáticos e alcadienos em concentração de 10 ppbv. As concentrações das curvas analíticas foram produzidas utilizando um multicalibrador da Thermo Environmental Instruments Inc, modelo $146 \mathrm{C}$, diluindo o padrão certificado em nitrogênio 5.0. As concentrações da curva analítica variaram de 0,92 a $9,83 \mathrm{~g} \mathrm{~m}^{-3}$ (ou 0,75 a 2,0 ppbv) considerando o composto de menor número de carbonos na mistura (etano) e o de maior número de carbonos (1,3,5-trimetilbenzeno). O limite de detecção foi de 0,01 ppbv.

\section{Tratamento estatístico}

Estatística descritiva foi utilizada para calcular porcentagem, média e desvio-padrão dos níveis de COV e ozônio na atmosfera de estudo. A concordância entre as medidas do coletor passivo e ativo de ozônio foi avaliada utilizando o Coeficiente de Correlação Intraclasse (ICC) com intervalo de confiança de 95\% (IC95\%). Para avaliar a diferença entre as concentrações de ozônio dos seis pontos de coleta distribuídos na área urbana de Araraquara foi utilizada análise de variância (ANOVA) de um fator e teste t-student para comparar a diferença das médias de ozônio na safra e entressafra. Como as concentrações de COV (ativo e passivo) apresentaram distribuição não-paramétrica foi aplicado o teste de Wilcoxon para verificar se existiu diferença entre os níveis desses poluentes na safra e entressafra (coleta ativa e passiva) e teste de Kurskal-Wallis para avaliar a diferença das médias de COV nos 6 pontos (coletor passivo). Análise de componentes principais (ACP) foi aplicada em dois conjuntos de dados: (1) concentrações de COV e ozônio da amostragem passiva e (2) concentrações de COV da amostragem ativa, ozônio, $\mathrm{NO}, \mathrm{NO}_{2}$ e variáveis meteorológicas da estação automática da CETESB. O número de amostras $(\mathrm{N})$ estatisticamente válidas para aplicação da ACP deve ser igual a $\mathrm{N}>30+(\mathrm{k}+3) / 2$, onde k é o número de variáveis. ${ }^{23}$ As análises foram realizadas no software Programa R versão 3.1.3. ${ }^{24}$

\section{RESULTADOS E DISCUSSÕES}

\section{Especiação dos COV na atmosfera estudada}

Os hidrocarbonetos identificados neste estudo pertencem à classe dos alcanos, alcenos, alcadienos e aromáticos, correspondendo compostos entre C2 - C10. A Tabela 2 apresenta concentrações médias 
dos COV identificados na safra e entressafra de cana-de-açúcar em amostras do coletor ativo. Verificou-se diferença estatisticamente significante nas concentrações de etilbenzeno, $m, p$-xileno, estireno, 1,3,5-trimetilbenzeno e 1,2,4-trimetilbenzeno entre safra e entressafra, $\mathrm{p}<0,05$ (Tabela 2). As concentrações dos COV variaram entre 0,10 a $92 \mathrm{ppb}$ e os compostos mais abundantes foram d-limoneno e tolueno, com médias de 30 e 1,8 ppb, respectivamente.

Tabela 2. Média das concentrações de COV (ppb) em atmosfera urbana sob influência de emissões da agroindústria canavieira na safra e entressafra de cana-de-açúcar de 2011/12 com respectivo desvio-padrão entre parênteses e valor de p do teste de Wilcoxon. Tipo de amostragem: coleta ativa de $24 \mathrm{~h}$ utilizando tubos adsorventes; local de coleta: SESA (Figura 1a)

\begin{tabular}{lccc}
\hline Composto & Safra* & Entressafra* & Valor de p \\
\hline Benzeno & $0,506(0,434)$ & $1,06(1,52)$ & 0,046 \\
Tolueno & $0,855(0,66)$ & $2,60(5,93)$ & 0,092 \\
Etilbenzeno & $0,199(0,157)$ & $0,675(1,58)$ & 0,001 \\
m,p-Xileno & $0,235(0,213)$ & $0,756(1,11)$ & 0,000 \\
o-Xileno & $0,221(0,172)$ & $0,479(0,734)$ & 0,245 \\
Estireno & $0,096(0,098)$ & $0,218(0,626)$ & $<0,001$ \\
1,3,5-Trimetilbenzeno & $0,161(0,573)$ & $0,184(0,285)$ & $<0,001$ \\
1,2,4-Trimetilbenzeno & $0,197(0,193)$ & $0,552(0,930)$ & 0,006 \\
1,4-Diclorobenzeno & $0,065(0,059)$ & $0,058(0,086)$ & 0,465 \\
Naftaleno & $0,063(0,050)$ & $0,116(0,185)$ & 0,993 \\
d-Limoneno & $5,43(13,8)$ & $6,38(18,1)$ & 0,988 \\
\hline Total & 8,03 & 13,0 & \\
\hline
\end{tabular}

$* \mathrm{~N}=72$.

Considerando as amostras da coleta passiva dos períodos de safra $(\mathrm{N}=18)$ e entressafra $(\mathrm{N}=18)$ nos 6 locais do estudo, foram encontrados os mesmos COV da amostragem ativa na amostragem passiva e diferença estatisticamente significativa entre safra e entressafra na quantidade dos seguintes COV acumulados nos tubos: benzeno, etilbenzeno, $m, p$-xileno e d-limoneno, sendo maiores na entressafra. A variação nas concentrações dos COV deve estar associada à diversidade de fontes de emissão (fontes fixas, móveis, sazonais), tempo de meia vida do COV na atmosfera e as condições ambientais de dispersão dos poluentes. ${ }^{17} \mathrm{~A}$ distribuição espacial dos COV nos seis pontos de coleta não apresentou diferença estatisticamente significante $(\mathrm{p}>0,05)$.

Em geral, os veículos automotores são a principal fonte de emissão de poluentes atmosféricos em ambiente urbano. ${ }^{17,25}$ Concentrações elevadas de tolueno, $o$-xileno e 1,2,4 trimetilbenzeno foram encontradas durante tráfego de veículos à gasolina, ${ }^{26}$ enquanto o etanol foi o composto mais abundante de emissão de veículos à álcool seguido por 1 e 2-propanol e aldeídos $\mathrm{C} 4$ - C9. ${ }^{27} \mathrm{O}$ d-limoneno é um monoterpeno emitido naturalmente pela vegetação em significativas quantidades e possui relevante reatividade fotoquímica na atmosfera, está na classe 5 de reatividade, com tempo de meia vida na atmosfera menor do que $15 \mathrm{~min} .{ }^{17} \mathrm{Na}$ quantidade em que foi encontrado, provavelmente, resultou da emissão de indústria de citrosuco que processa laranja, alimento rico em d-limoneno, na área urbana de Araraquara,

Na Tabela 3 apresentam-se concentrações totais de COV determinadas a partir da coleta com canisters em três situações distintas. Pode-se observar que as amostras durante a queima apresentaram concentrações superiores ao pós-queima tanto no ambiente rural como urbano (Tabela 3). As amostras durante-queima e pós-queima/ rural ocorreram no mesmo local, com intervalo de cerca de $8 \mathrm{~h}$ após a queima do canavial, por isso pode-se comparar essas amostras para identificar os principais COV de origem da queima da cana, como observado na Tabela 3.

Tabela 3. Concentração de COV (ppb) durante a queima (N=3) e pós-queima $(\mathrm{N}=3)$ de canaviais e em ambiente urbano de Araraquara, SP, nos meses de julho, agosto, setembro de 2011. Tipo de amostragem: coleta com Canisters; locais de coleta: Figura 1b

\begin{tabular}{lcccc}
\hline & $\begin{array}{c}\text { Área } \\
\text { Queimada* } \\
\text { (ha) }\end{array}$ & $\begin{array}{c}\text { Durante- } \\
\text { Queima }\end{array}$ & $\begin{array}{c}\text { Pós-Queima } \\
\text { Rural }\end{array}$ & $\begin{array}{c}\text { Pós-Queima } \\
\text { Urbano }\end{array}$ \\
\cline { 3 - 5 } & 4,75 & 45,3 & 30,1 & 15,6 \\
Julho & 14,97 & 228 & 7,89 & 8,18 \\
Agosto & 4,50 & 22,9 & 0,690 & 32,8 \\
Setembro & &
\end{tabular}

*Informação fornecida por funcionário de Usina de cana-de-açúcar.

O eteno foi o composto característico da queima de canaviais, pois em todas as amostras foi identificado em maiores concentrações, representando 51,7\% do total de COV na situação durante a queima (Tabela 4). Depois do eteno, as concentrações de etano e propeno também foram expressivas, representando cerca de $10 \%$ cada um do total de COV (Tabela 4), em função da amostra de agosto, que apresentou a maior concentração total (Tabela 3). Os COV mais abundantes no pós-queima/rural foram tolueno (16\%), 1,2,4-trimetilbenzeno $(15 \%)$ e $p, m$-xileno (10\%), em função, principalmente, das amostras de julho e agosto.

Os COV identificados nas amostras pós-queima do ambiente urbano apresentaram concentrações entre 0,03 a 5,5 ppb. A contribuição relativa dos COV nessas amostras teve predominância do eteno (13\%), seguida pelo butano (10\%) e isopentano (9,0\%), dados não apresentados na tabela. O eteno pode ser um composto característico da queima da cana-de-açúcar entre os hidrocarbonetos identificados.

\section{Avaliação do coletor passivo}

A Figura 2 apresenta as concentrações de ozônio do coletor passivo Ogawa e ativo da estação automática da CETESB. O valor de ICC foi de 0,966 (IC95\% 0,757 a 0,995) e a correlação entre coleta ativa e passiva foi de 0,951 . Esses resultados mostram que apesar de valores relativamente maiores da coleta passiva em relação a ativa (Figura 2), a concordância e correlação entre esses amostradores é alta, corroborando outros estudos..$^{28,29}$ Segundo Krupa e Legge, ${ }^{30}$ nitrito é o absorvente mais satisfatório para coleta passiva de ozônio na atmosfera comparado aos absorventes p-ATP (p-acetamidofenol), índigo carmine e DPE (1,2-bis(4-piridil)etileno). A solução de impregnação de nitrito contém componentes para garantir que a reação entre os íons nitrito e ozônio seja específica, pois essa reação é pH-dependente, ou seja, a taxa da reação aumenta com aumento do pH. Além disso, a alcalinidade da solução de impregnação elimina a interferência do peróxido de hidrogênio, importante oxidante atmosférico que reage com nitrito em $\mathrm{pH}<7$. Nas quantidades em que são encontrados na atmosfera, outros agentes oxidantes, como dióxido de enxofre e nitrato peroxiacetílico $(P A N)$, não causam interferência na reação entre ozônio e nitrito. ${ }^{29}$

\section{Perfil de ozônio troposférico na safra e entressafra de cana-de- açúcar}

Durante a safra de cana-de-açúcar, concentrações de ozônio variaram de 33,07 a 79,61 $\mu \mathrm{g} \mathrm{m}^{-3}$, com média de 52,93 $\pm 12,39 \mu \mathrm{g}$ $\mathrm{m}^{-3}$, e na entressafra de 22,23 a $89,56 \mu \mathrm{g} \mathrm{m}^{-3}$, com média de 52,61 \pm 25,65 $\mu \mathrm{g} \mathrm{m}^{-3}$. Na Figura 3 encontram-se os níveis de ozônio durante 
Tabela 4. Soma das concentrações de COV (ppb) durante queima ( $\mathrm{N}=3$ ) e pós-queima/rural (N=3) em ambiente rural na safra de cana $2011 \mathrm{em}$ Araraquara, SP e a composição relativa dos COV durante queima e pós-queima dos canaviais. Tipo de amostragem: coleta com Canisters. Locais de coleta: Figura 1b

\begin{tabular}{|c|c|c|c|c|}
\hline \multirow[b]{2}{*}{ Compostos } & \multicolumn{2}{|c|}{ Concentração (ppb) } & \multicolumn{2}{|c|}{ Composição relativa (\%) } \\
\hline & $\begin{array}{c}\text { Durante- } \\
\text { Queima }\end{array}$ & Pós-Queima & $\begin{array}{c}\text { Durante- } \\
\text { Queima }\end{array}$ & Pós-Queima \\
\hline Eteno & 153 & 2,65 & 51,7 & 6,85 \\
\hline Etano & 33,0 & nd & 11,1 & -- \\
\hline Propeno & 29,8 & nd & 10,1 & -- \\
\hline Butano & 14,7 & 0,047 & 4,97 & 0,121 \\
\hline Tolueno & 10,0 & 6,15 & 3,38 & 15,9 \\
\hline 1,2,4-TMB* & 6,20 & 5,91 & 2,09 & 15,3 \\
\hline p,m-Xileno & 5,97 & 4,01 & 2,02 & 10,4 \\
\hline Estireno & 5,99 & 2,44 & 2,02 & 6,30 \\
\hline o-Xileno & 3,59 & 3,39 & 1,21 & 8,76 \\
\hline Etilbenzeno & 4,73 & 1,91 & 1,60 & 4,94 \\
\hline Propano & 6,54 & nd & 2,21 & -- \\
\hline 1,2,3-ТMB & 2,62 & 2,59 & 0,885 & 6,69 \\
\hline Benzeno & 2,81 & 2,10 & 0,949 & 5,43 \\
\hline Isopreno & 3,27 & 1,24 & 1,10 & 3,20 \\
\hline Hexano & 1,65 & 1,42 & 0,557 & 3,67 \\
\hline $\begin{array}{l}\text { 1-Prope- } \\
\text { nilbenzeno }\end{array}$ & 2,52 & nd & 0,851 & -- \\
\hline Buteno & 2,10 & 0,41 & 0,709 & 1,06 \\
\hline 1,3,5-ТМB & 2,45 & nd & 0,828 & -- \\
\hline $\begin{array}{l}\text { Isopropilben- } \\
\text { zeno }\end{array}$ & nd & 2,43 & -- & 6,28 \\
\hline Propeno & 1,68 & nd & 0,568 & -- \\
\hline Feniletino & 1,53 & nd & 0,517 & -- \\
\hline Isobutano & 0,342 & 0,349 & 0,116 & 0,90 \\
\hline Hex-1-eno & nd & 0,677 & -- & 1,75 \\
\hline Octano & nd & 0,710 & -- & 1,85 \\
\hline $\begin{array}{l}\text { trans-But-2- } \\
\text { eno }\end{array}$ & 0,591 & nd & 0,200 & -- \\
\hline $\begin{array}{l}\text { 2-Metil-pent- } \\
\text { 2-eno }\end{array}$ & 0,350 & nd & 0,118 & -- \\
\hline cis-But-2-eno & 0,249 & nd & 0,084 & -- \\
\hline $\begin{array}{l}\text { Pent-3-en- } \\
\text { 1-ino }\end{array}$ & 0,221 & nd & 0,075 & -- \\
\hline Hept-1-eno & 0,167 & nd & 0,056 & -- \\
\hline cis-Pent-2-eno & 0,165 & nd & 0,056 & -- \\
\hline Heptano & 0,105 & 0,090 & 0,035 & -- \\
\hline $\begin{array}{l}\text { Metilciclo- } \\
\text { exano }\end{array}$ & nd & 0,175 & -- & -- \\
\hline 3-Metilexano & nd & 0,010 & -- & -- \\
\hline Total & 296 & 38,7 & 100 & 100 \\
\hline
\end{tabular}

nd = não detectado. $*$ Trimetilbenzeno.

os períodos de amostragem ativa e passiva. A variação dessas concentrações é relativamente elevada, uma vez que a formação de ozônio troposférico depende das condições meteorológicas, como radiação solar, e das concentrações de seus precursores. ${ }^{16}$ Por isso, pode-se observar grande variação nas médias de ozônio no período de estudo. Verificou-se maior pico de ozônio na entressafra (Figura 3b), porém as médias horárias de ozônio na safra foram maiores em comparação com a entressafra (Figura 3a). Análise de variância (ANOVA) de um fator considerando as médias de concentrações de ozônio nos seis pontos de coleta na cidade de Araraquara mostrou que não houve diferença estatisticamente significativa na distribuição espacial de n Coletor passivo $\quad$ Coletor ativo

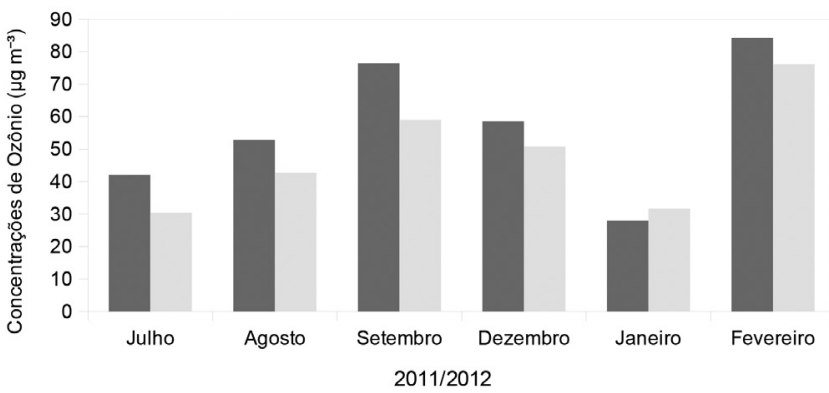

Figura 2. Concentrações de ozônio por amostragem ativa (da Cetesb) $e$ passiva na cidade de Araraquara, SP

ozônio troposférico ( $\mathrm{p}>0,05)$, ou seja, pode-se considerar que as concentrações de ozônio se distribuíram homogeneamente na atmosfera urbana de Araraquara. A partir disso, avaliou-se a diferença das médias de ozônio na safra e entressafra aplicando-se o teste t-student e verificou-se que não existiu diferença estatisticamente significativa entre a safra e entressafra de cana-de-açúcar de 2011/12 (p>0,05). Embora a agroindústria de cana-de-açúcar contribua como fonte de emissão de precursores de ozônio, essas quantidades não devem ser suficientes para causar aumento significativo desse poluente na safra comparada ao período de entressafra. Assim também concluíram Ziemke et al. ${ }^{31}$ sobre a associação direta entre queima de biomassa e concentrações de ozônio em regiões tropicais, com picos máximos em setembro e outubro, em 2004 e 2008, destacando que as emissões de queima de biomassa são importantes para a formação do ozônio, porém não são majoritárias.
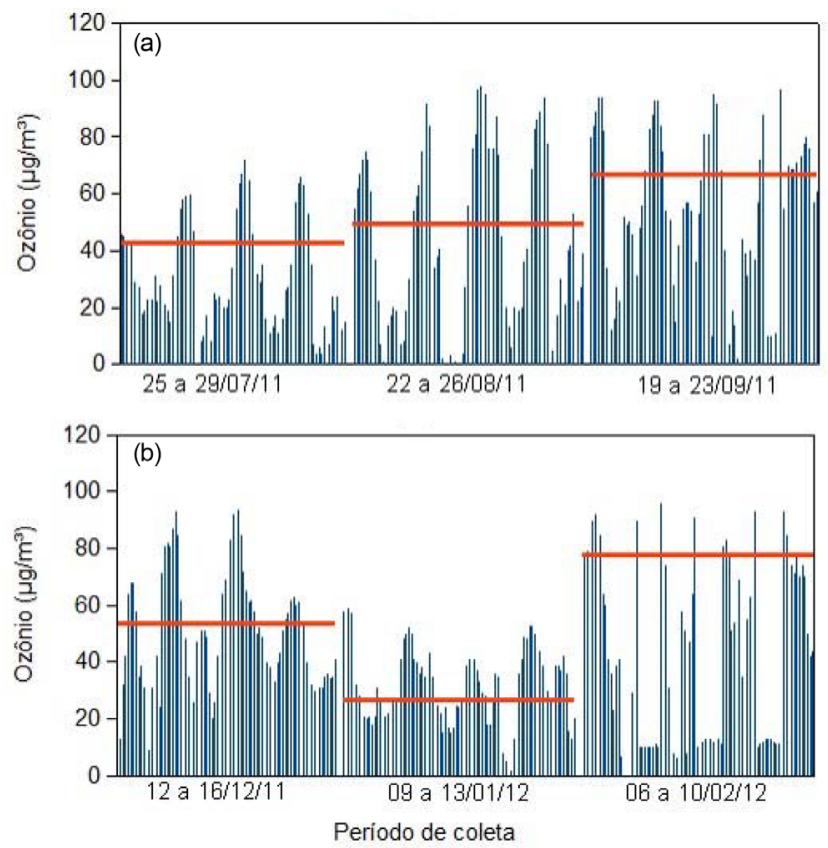

Figura 3. Médias horárias de ozônio da coleta ativa (dados Cetesb) (em azul) e médias de ozônio de 4 dias (em vermelho) da coleta passiva na safra (a) e entressafra (b)

Em contraste com resultados deste estudo, Debaje e Kakade ${ }^{32}$ encontraram aumento de $11 \%$ nas concentrações de ozônio no período de moagem da cana-de-açúcar na Índia, atribuído ao aumento de precursores de ozônio em amostras coletadas próximas a indústria sucroalcooleira. No Brasil, foram identificados níveis de ozônio troposférico de até $80 \mathrm{ppb}$, ou cerca de $171 \mu \mathrm{g} \mathrm{m}^{-3}$, à $2 \mathrm{~km}$ de altura 
durante o período de queima da cana em setembro de 1988 em área rural no oeste do estado de São Paulo. ${ }^{33}$ A queima de biomassa da agroindústria sucroalcooleira tem sido apontada como umas das principais fontes de emissão atmosférica dessa atividade, porém é importante destacar que a atividade canavieira possui outras fontes de precursores de ozônio como veículos à diesel usados para transporte, colheita e plantio, queima do bagaço e palha de cana para geração de energia, etc. Além do mais, no estado de São Paulo a prática da queimada pré-colheita será eliminada em breve. A sazonalidade desempenha grande influência na variação das concentrações de ozônio, com máximas mensais no período de setembro a outubro em Araraquara. ${ }^{20}$ Tem-se observado máximas de ozônio no período conhecido como spring maximum, ${ }^{34}$ em que as condições meteorológicas são mais favoráveis à formação de ozônio. Em relação à agroindústria canavieira, as maiores emissões ocorrem no período de julho a setembro na safra do Sudeste e, a partir de outubro, as atividades da safra da cana diminuem acompanhadas pelo período chuvoso. A safra 2011, em particular, encerrou-se no final de outubro por causa da baixa produtividade da cana.

\section{Análise de componentes principais}

Análise de componentes principais (ACP) foi realizada utilizando dois conjuntos de dados, o primeiro formado por 8 variáveis e 36 amostras, e o segundo por 17 variáveis e 144 amostras. Em ambas as análises foram retidos os componentes principais com variância $>5 \%$ e apenas os autovalores $>0,20$ foram apresentados. A Tabela 5 apresenta a ACP do primeiro conjunto de dados, na qual a componente PC1 explica 70\% de toda variância do conjunto e é caracterizada pelos COV que apresentam os maiores pesos. PC 2 explica $13 \%$ da variância total e é caracterizada pelo d-limoneno, que apresentou alto peso. PC3 explica $12 \%$ da variância total e o ozônio apresenta o maior peso.

Tabela 5. Autovetores da matriz de correlação (PC1, PC2, PC3) e respectivos autovalores, variâncias total e cumulativa. Amostras da coleta passiva de COV em ambiente urbano na safra e entressafra de 2011/12 em Araraquara, SP

\begin{tabular}{lccc}
\hline \multirow{2}{*}{ Compostos } & \multicolumn{3}{c}{ Componentes principais } \\
\cline { 2 - 4 } & PC1 & PC2 & PC3 \\
\hline Ozônio & 0,21 & $-0,87$ \\
Benzeno & $-0,40$ & & \\
Tolueno & $-0,39$ & & \\
Etilbenzeno & $-0,39$ & & 0,28 \\
m,p-Xileno & $-0,41$ & & \\
o-Xileno & $-0,38$ & & 0,35 \\
1,2,4-TMB* & $-0,41$ & & \\
d-Limoneno & & $-0,98$ & 12 \\
Variância total (\%) & 70 & 13 & 95 \\
Cumulativa (\%) & 70 & 83 & \\
\hline
\end{tabular}

*Trimetilbenzeno.

Na Tabela 6, a ACP foi aplicada ao conjunto de dados da coleta ativa. Além das concentrações de ozônio e COV, foram incluídas variáveis meteorológicas (VV, UR e temperatura) e concentrações de $\mathrm{NO}$ e $\mathrm{NO}_{2}$. A primeira componente principal (PC1') explicou 38,5\% da variância dos dados e todos os $\mathrm{COV}$ apresentaram pesos negativos e equivalentes, como no primeiro conjunto de análise. Esses COV devem estar associados ao mesmo tipo de fonte de emissão. A segunda componente principal (PC2') explica $18,4 \%$ de toda variância dos dados e está associada à fotoquímica do ozônio, em que $\mathrm{O}_{3}, \mathrm{NO}, \mathrm{NO}_{2}$ e temperatura apresentam os maiores pesos. A umidade relativa (UR) tem peso relativamente baixo nessa componente. PC3' explica 8,5\% da variância total, em que d-limoneno e as variáveis meteorológicas apresentaram os maiores pesos, sendo que a temperatura tem a maior importância. PC4' está associada aos precursores de ozônio, NOx e etilbenzeno com pesos negativos e tolueno, 1,4-diclorobenzeno e d-limoneno com pesos positivos.

Tabela 6. Autovetores da matriz de correlação (PC1', PC2', PC3' e PC4') e respectivos autovalores, variâncias total e cumulativa. Amostras da coleta ativa de COV em ambiente urbano na safra e entressafra de 2011/12, dados meteorológicos e de concentração de poluentes da estação de monitoramento da CETESB em Araraquara, SP

\begin{tabular}{|c|c|c|c|c|}
\hline \multirow{2}{*}{ Compostos } & \multicolumn{4}{|c|}{ Componentes principais } \\
\hline & PC1' & PC2' & PC3' & PC4' \\
\hline $\mathrm{VV}^{\mathrm{a}}$ & & 0,38 & $-0,38$ & \\
\hline $\mathrm{UR}^{\mathrm{b}}$ & & $-0,22$ & $-0,38$ & \\
\hline Temperatura & & 0,29 & 0,51 & \\
\hline Ozônio & & 0,47 & 0,23 & \\
\hline NO & & $-0,33$ & & $-0,40$ \\
\hline $\mathrm{NO}_{2}$ & & $-0,38$ & & $-0,41$ \\
\hline Benzeno & $-0,37$ & & & \\
\hline Tolueno & $-0,21$ & & 0,30 & 0,25 \\
\hline Etilbenzeno & $-0,21$ & & 0,25 & $-0,32$ \\
\hline m,p-Xileno & $-0,37$ & & & \\
\hline o-Xileno & $-0,37$ & & & \\
\hline Estireno & $-0,21$ & & & \\
\hline $1,3,5-\mathrm{TMB}^{\mathrm{c}}$ & $-0,36$ & & & \\
\hline $1,2,4-\mathrm{TMB}$ & $-0,37$ & & & \\
\hline d-Limoneno & & $-0,27$ & 0,39 & 0,41 \\
\hline 1,4 Diclorobenzeno & & $-0,37$ & & 0,39 \\
\hline Naftaleno & $-0,37$ & & & \\
\hline Variância total (\%) & 39 & 18 & 8,5 & 6,4 \\
\hline Cumulativa (\%) & 39 & 57 & 66 & 72 \\
\hline
\end{tabular}

${ }^{a}$ Velocidade do Vento. ${ }^{\mathrm{b}}$ Umidade Relativa do ar. ${ }^{\mathrm{c}}$ Trimetilbenzeno.

\section{CONCLUSÃO}

Durante o período deste estudo, as concentrações de ozônio troposférico na safra e entressafra de cana-de-açúcar não apresentaram diferença significativa na atmosfera urbana de Araraquara. Esse fato não descarta a contribuição dos precursores emitidos na agroindústria sucroalcooleira para a formação de ozônio, mas aponta que não desempenham papel determinante para o aumento dos níveis desse poluente. A análise de componentes principais mostrou clara discriminação entre as concentrações de COV e a atividade fotoquímica de formação de ozônio e variáveis meteorológicas na área urbana de Araraquara. Além do mais, revelou que as concentrações de d-limoneno possui fonte de emissão distinta dos demais COV. Comparação entre os COV durante a queima e pós-queima/rural supõe que o eteno é o composto característico das queimas de cana-de-açúcar pré-corte.

\section{AGRADECIMENTOS}

Os autores agradecem a FAPESP (Fundação de Ampara à Pesquisa do Estado de São Paulo) pela concessão de uma bolsa de 
mestrado. Agradecemos à Prof ${ }^{a}$. Dra. M. F. Andrade por disponibilizar o Laboratório de Análise dos Processos Atmosféricos (Lapat) IAG/USP para análise de ozônio e ao apoio técnico de R. Astolfo. Agradecemos o apoio institucional para o trabalho de campo do Serviço Especial de Saúde de Araraquara (SESA) e do Departamento de Saúde Ambiental, ambos da Faculdade de Saúde Pública da USP. Também agradecemos à CETESB de Araraquara pela autorização para utilização do espaço da estação automática de monitoramento da qualidade do ar da cidade e pelo respaldo para coleta de poluentes nas usinas de cana-de-açúcar.

\section{REFERÊNCIAS}

1. Companhia Nacional de Abastecimento; Acompanhamento da safra brasileira de cana-de-açúcar - v. 1; Conab: Brasília, 2013. Disponível em: http://www.conab.gov.br.

2. http://www.dsr.inpe.br/laf/canasat/colheita.html, acessado em julho de 2016.

3. www.iea.sp.gov.br/RelatórioConsolidado1512.pdf, acessado em julho de 2016.

4. Kirchhoff, V. W. J. H.; Marinho, E. V. A.; Dias, P. L. S.; Pereira, E. B.; Calheiros, R.; André, R.; Volpe, C.; J. Atmos. Chem. 1991, 12, 87.

5. Marinho, E. V. A.; Kirchhoff, V. W. J. H.; Revista Brasileira de Geofísica 1991, 9, 107.

6. Machado, C. M. D.; Tese de doutorado, Universidade Estadual Paulista, Brasil, 2007.

7. Ribeiro, H.; Rev. Saúde Pública 2008, 42, 370.

8. Ribeiro, H.; de Assunção, J. V.; Revista de Estudos Avançados 2002, 16, 125.

9. Cançado, J. E. D.; Saldiva, P. H. N.; Pereira, L. A.; Lara, L. B.; Artaxo, P.; Martinelli, L. A.; Arbex M. A.; Zanobetti, A.; Braga, A. L.; Environ. Health Perspect. 2006, 14, 725.

10. Lopes, M. L. A.; Tese de doutorado, Universidade de São Paulo, Brasil, 2010.

11. Hall, D.; Wu, C-Y.; Hsu, Y-M.; Stormer, J.; Engling, G., Capeto, K.; Wang, J.; Brown, S.; Li, H-W.; Yu, K-M.; Atmos. Environ. 2012, 55, 164.

12. da Rocha, G. O.; Franco, A.; Allen, A. G.; Cardoso, A. A. J.; Geophys. Res. 2003, 108.

13. Oppenheimer, C.; Tsanev, V. I.; Allen, A. G.; McGonigle, A. J.; Cardoso, A. A.; Wiatr, A.; de Mello Dias, C.; Environ. Sci. Technol. 2004, 38, 4557.
14. Franca, D. D. A.; Longo, K. M.; Neto, T. G. S.; Santos, J. C.; Freitas, S. R.; Rudorff, B. F.; Carvalho, J. A.; Atmosphere 2012, 3, 164.

15. Francisco, A. P.; Dissertação de Mestrado, Universidade de São Paulo, Brasil, 2012.

16. Bowman, F. M.; Seinfeld, J. H.; J. Geophys. Res.: Atmos. 1994, 99, 5309.

17. Kansal, A.; J. Hazard. Mater. 2009, 166, 17.

18. Ugucione, C.; Machado, C. D. M. D.; Cardoso, A. A.; Quim. Nova 2009, 32,1829 .

19. Garcia, G.; Allen, A. G.; Cardoso, A. A.; J. Environ. Monit. 2010, 12, 1325 .

20. http://ar.cetesb.sp.gov.br/publicacoes-relatorios/, acessada em julho de 2015.

21. Campos, V. P.; Cruz, L. P. S.; Alves, E. M.; Santos, T. S.; Silva, A. D.; Santos, A. C. C. dos; Lima, A. M. V.; Paixão, C. S.; Santos, D. C. M. B.; Brandão, D. S.; Andrade, E. J. S.; Moreira, J. I. Jr.; Conceição, K. C. S.; Ramos, M. S.; Pontes, M. C. G.; Amaral, M. F.; Mattos, R. R.; Quim. Nova 2006, 29, 872

22. Cao, X.-L.; Hewitt, C. N.; Atmos. Chem. 1993, 27A, 1865.

23. Andrade, M. F.; Tese de Doutorado, Universidade de São Paulo, Brasil, 1993.

24. R Core Team; R: A language and environment for statistical computing, R Foundation for Statistical Computing: Austria, 2015.

25. Orlando, J. P.; Alvim, D. S.; Yamazaki, A.; Corrêa, S. M.; Gatti, L. V.; Sci. Total Environ. 2010, 408, 1612.

26. Olson, D. A.; Hammond, D. M.; Seila, R. L.; Burke, J. M.; Norris, G. A.; Atmos. Environ. 2009, 43, 5647.

27. Colón, M.; Pleil, J. D.; Hartlage, T. A.; Guardani. M. L.; Martins, M. H.; Atmos. Environ. 2001, 35, 4017.

28. Gibson, M. D.; Guernsey, J. R.; Beauchamp, S.; Waug, D.; Heal, M. R.; Brook, J. R.; Maher, R.; Gagnon, G. A.; Mcpherson, J. P.; Bryden, B.; Goul, R.; Terashim, M.; J. Air Waste Manage. Assoc. 2009, 59, 310.

29. Koutrakis, P.; Wolfson, J. M.; Bunyaviroch, A.; Froehlich, S. E.; Hirano, K.; Mulik, J. D.; Anal. Chem. 1993, 65, 209.

30. Krupa, S. V.; Legge, A. H.; Int. J. Environ. Pollut. 2000, 107, 31.

31. Ziemke, J. R.; Chandra, S.; Duncan, B. N.; Schoeber, M. R.; Torres, O.; Damon, M. R.; Bhartia, P. K.; Geophys. Res. Lett. 2009, 36, 1.

32. Debaje, S. B.; Kakade, A. D.; J. Hazard. Mater. 2009, 161, 686.

33. Kirchhoff, V. W. J. H.; Marinho, E. V. A.; Atmos. Environ. 1994, $28,69$.

34. Vingarzan, R.; Atmos. Environ. 2004, 38, 3431. 